\title{
Pseudohypoparathyroidism with Raised Plasma Alkaline Phosphatase
}

\author{
R. D. COHEN and F. P. VINCE \\ From the Medical Unit and the Department of Metabolism and Endocrinology, \\ The London Hospital, London E.1
}

Pseudohypoparathyroidism was described by Albright and his colleagues in 1942 . These workers showed that some of the clinical and biochemical manifestations of the condition were due to endorgan insensitivity to parathyroid hormone, and suggested that hypersecretion of the hormone would occur in response to the low plasma calcium level resulting from this insensitivity. This idea was supported by the finding of hyperplastic parathyroid glands in some of these patients (Elrick et al., 1950). However, 5 cases have so far been reported in which there have been raised plasma alkaline phosphatase levels and radiological and, in some cases, histological evidence of osteitis fibrosa (Garceau and Miller, 1956; Kolb and Steinbach, 1962; Costello and Dent, 1963; Bell, Gerard, and Bartter, 1963). In these cases at least it seems likely that, though the kidney is insensitive to the hormone, the bones remain sensitive. If this is so, the low plasma calcium level requires explanation.

We present a further case of this type and discuss this problem in the light of recent concepts of calcium homeostasis.

\section{Case Report}

A 13-year-old boy, the fourth of 8 sibs, presented in 1963 with a dull aching pain in the right lower abdomen. An inguinal hernia was found and repaired. He continued to complain of vague aching in the lower abdomen, hips, and thighs, and refused to play games at school. By January 1966 he was having difficulty in walking, with stiffness in the hips and pain in the upper parts of the thighs. He also noticed cramps in the limbs and, occasionally, tingling round the mouth. He had passed urine once during the night all his life. He was subject to mild attacks of asthma, and at the age of 3 years had had an illness which was thought to be meningitis.

Physical examination (in April 1966 age 15 years 7 months). Height $162.5 \mathrm{~cm}$. (1 SD below mean height for age), span $165 \mathrm{~cm}$. (father's height $174 \mathrm{~cm}$., mother's

Received July 29, 1968. height $156 \mathrm{~cm}$.). Weight $53.9 \mathrm{~kg}$. (normal). The face was flat, round, and expressionless, and there was hypertelorism. The teeth were normal. Hands were normally proportioned, with normal metacarpals. There was some splaying-out of the lower ribs, but the costochondral junctions were not enlarged. There was gross genu valgum, and with the knees touching, the feet were separated by $10 \mathrm{~cm}$. Walking was painful; he took short shuffling steps. He had attended a normal school, but was thought by his parents to be mentally slower than the rest of his family. Puberty had begun, but the testes were small. Blood pressure $120 / 75 \mathrm{~mm}$. $\mathrm{Hg}$; Trousseau's sign and Chvostek's sign were negative. There were no signs of thyroid disease, and the thyroid gland was not palpable. Physical examination was otherwise normal.

Radiology. $X$-ray of the skull showed widelyspaced orbits and enormous frontal sinuses (Fig. 1). The hands showed subperiosteal erosions, most marked in the fingers (Fig. 2a). The femora were grossly abnormal; there was widening of the epiphysial plates at the upper ends of each femur, with irregularity almost entirely on the metaphysial side, as may be seen in hyperparathyroidism (Costello and Dent, 1963). There was a slipped epiphysis on the left side (see Fig. 4). The knees, however, were normal, the epiphysial lines at the lower ends of the femora and upper ends of the tibiae being narrow, regular, and clearly demarcated.

The presence of subperiosteal erosions in the hands and the appearance of the upper ends of the femora, together with the absence of any striking changes in the knees, were thought to be characteristic of hyperparathyroidism occurring in growing bones of this age.

Biochemical and other investigations. $\mathrm{Hb}$, white cell count, and blood film were normal. ESR $20 \mathrm{~mm}$./hr. Routine urine examination and culture were normal. Plasma electrolytes: $\mathrm{Na} 143 \mathrm{mEq} / \mathrm{l}$, K $4.3 \mathrm{mEq} / 1$., $\mathrm{HCO}_{3}^{-} 27 \mathrm{mEq} / 1 ., \mathrm{Cl}-99 \mathrm{mEq} / 1$. Plasma albumin $4 \cdot 8 \mathrm{~g} . / 100 \mathrm{ml}$., globulin $3.2 \mathrm{~g} . / 100 \mathrm{ml}$. Faecal fat excretion less than $1 \mathrm{~g}$./day over a 5-day collection period. Maximum plasma xylose after standard load was $44 \mathrm{mg}$. $/ 100 \mathrm{ml}$. (normal). Fasting plasma calcium initially lay between 8.9 and $9.5 \mathrm{mg} . / 100 \mathrm{ml}$., i.e. at the 
lower limit of normal. Plasma magnesium $1.3 \mathrm{mEq} / 1$. Plasma phosphorus (Fig. 3) was consistently raised at about $6.0 \mathrm{mg} . / 100 \mathrm{ml}$. Plasma alkaline phosphatase initially lay between 31 and $51 \mathrm{KA}$ units $/ 100 \mathrm{ml}$. (Fig. 3). Blood urea $21 \mathrm{mg} .100 \mathrm{ml}$., creatinine clearance $144 \mathrm{ml}$./ min. Urine osmolality after 18 hours of water deprivation $610 \mathrm{mOsm}$. $/ \mathrm{kg}$. (normal $>900 \mathrm{mOsm}$. $/ \mathrm{kg}$.). After a standard ammonium chloride load $(0.1 \mathrm{~g} . / \mathrm{kg}$.), the minimum urinary $p H$ was $5 \cdot 0$. Urinary amino acid chromatogram was normal. Glucose tolerance test: fasting total reducing sugars $84 \mathrm{mg} .100 \mathrm{ml}$., at 40 minutes $117 \mathrm{mg} . / 100 \mathrm{ml}$, at 120 minutes $96 \mathrm{mg} . / 100 \mathrm{ml}$. There was no glycosuria during the test. Phosphorus excretion index (Nordin and Fraser, 1960) - 0.21 and $-0 \cdot 22$ (normal range $\pm 0 \cdot 09$ ). Plasma uric acid $1 \cdot 7$, $1.9,2.0 \mathrm{mg} . / 100 \mathrm{ml}$. 24-hour urine urate excretion $348 \mathrm{mg}$. Urinary calcium varied between 50 and 150 mg. in 24 hours on an ordinary ward diet.

Bone biopsy. A bone biopsy was taken from the iliac crest 24 hours after administration of tetracycline $1 \mathrm{~g}$. The specimen was small, but included the epiphysial region. 'Distinct osteoid margins to bone (1-2 bright laminae), but not grossly excessive; width of the order of $10 \mu$. Calcium was being deposited in large granules in the matrix of the cartilage, which was not proliferating and swelling in the usual amount seen in the

$a$
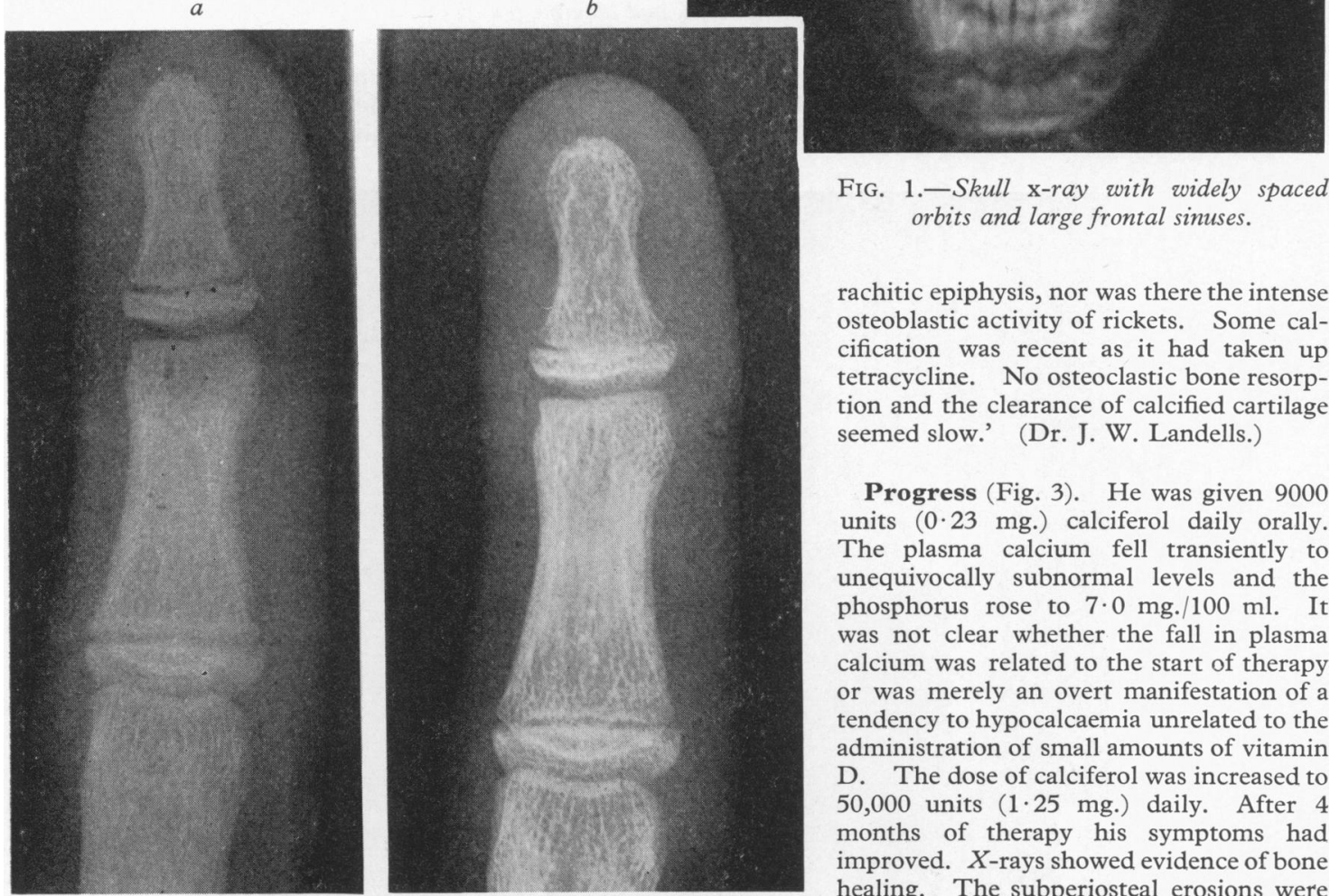

FIG. 1.-Skull $\mathrm{x}$-ray with widely spaced orbits and large frontal sinuses.

rachitic epiphysis, nor was there the intense osteoblastic activity of rickets. Some calcification was recent as it had taken up tetracycline. No osteoclastic bone resorption and the clearance of calcified cartilage seemed slow.' (Dr. J. W. Landells.)

Progress (Fig. 3). He was given 9000 units $(0.23 \mathrm{mg}$.) calciferol daily orally. The plasma calcium fell transiently to unequivocally subnormal levels and the phosphorus rose to $7.0 \mathrm{mg} . / 100 \mathrm{ml}$. It was not clear whether the fall in plasma calcium was related to the start of therapy or was merely an overt manifestation of a tendency to hypocalcaemia unrelated to the administration of small amounts of vitamin D. The dose of calciferol was increased to 50,000 units (1.25 mg.) daily. After 4 months of therapy his symptoms had improved. $X$-rays showed evidence of bone healing. The subperiosteal erosions were less obvious (Fig. 2b), and the epiphysial cartilages were calcifying. Plasma calcium 


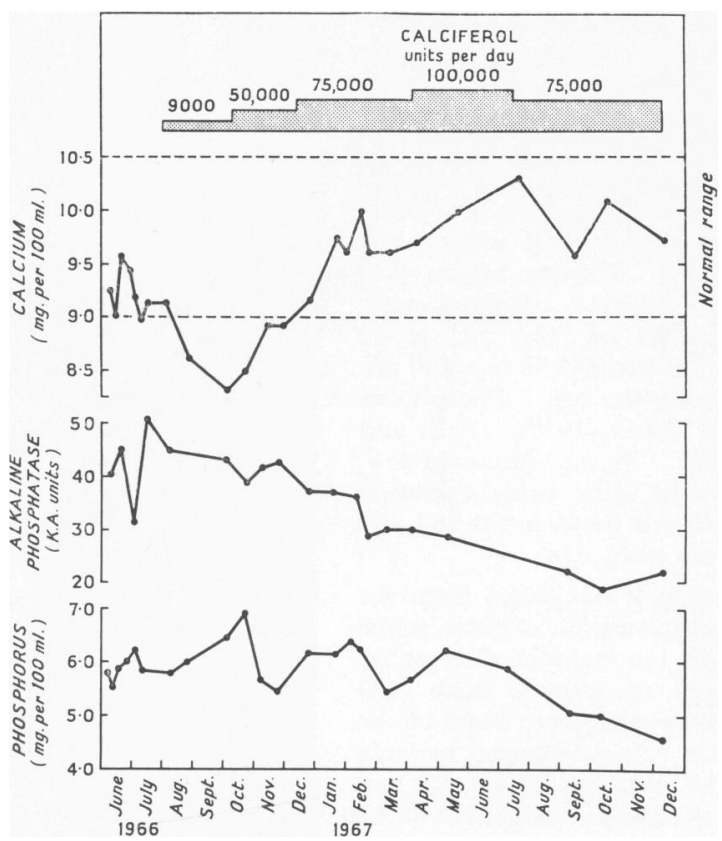

FIG. 3.-Response of plasma calcium, phosphorus, and alkaline phosphatase to treatment with calciferol.

and phosphorus had returned to their original levels and the alkaline phosphatase remained high. Calciferol was increased to 100,000 units $(2.5 \mathrm{mg}$.) daily, but on this dose his plasma calcium rose to $10.5 \mathrm{mg} . / 100 \mathrm{ml}$. He was given 100,000 units and 50,000 units on alternate days and has been maintained on this regimen. Bone

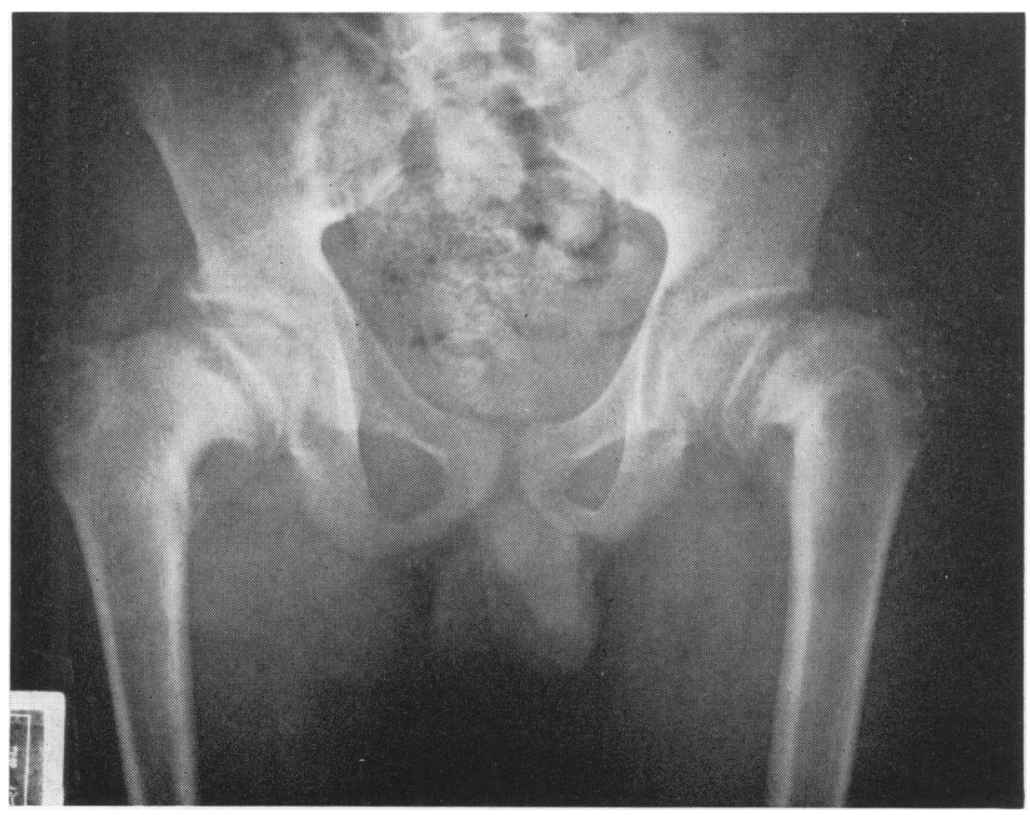

Fig. 4.-Pelvis, April 1966 (before treatment). 
healing has continued and the subperiostial erosions have disappeared (Fig. 5). $\mathrm{He}$ is asymptomatic. $\mathrm{He}$ has grown $3.8 \mathrm{~cm}$., but there has been little progress in his sexual development. Plasma calcium has remained within the normal range, and plasma phosphorus has progressively fallen and is now normal. Plasma alkaline phosphatase has fallen to $20 \mathrm{KA}$ units.

Family study. No physical characteristics were found in the parents and 7 sibs suggesting past or present bone disease or other definite features described in pseudohypoparathyroidism. Hypertelorism was not present in any other member. Plasma calcium, phosphorus, and alkaline phosphatase estimations all lay within the normal range. A dermatoglyphic study on the patient and his parents showed that the patient and his mother were normal. The father showed a distal $t$ triradius, a feature found rather more frequently in pseudohypoparathyroidism than in the general population (Forbes, 1964). In the absence of any other physical or chemical abnormalities, this feature was not considered to be of significance.

\section{Discussion}

This patient appears to have a form of pseudohypoparathyroidism in which the renal tubules are resistant to the action of parathyroid hormone, but in which the bones remain sensitive (Kolb and Steinbach, 1962).
He resembles very closely the case of Costello and Dent (1963) clinically, biochemically, and radiologically. In particular, both patients had a rachitic appearance of the epiphyses. Costello and Dent suggested that this appearance was misleading and was really due to osteitis fibrosa. In the present case a bone biopsy showed no features of rickets, but neither was there evidence of osteoclastic bone resorption. However, the marked phalangeal subperiosteal erosions and raised alkaline phosphatase strongly suggest osteitis fibrosa, and it may be that a larger bone biopsy, or one from a more satisfactory site, would have revealed evidence of this condition. It was felt that the absence of wide osteoid seams and the orderly arrangement of normal-looking cartilage cells of the epiphysial region made rickets unlikely.

If the osteitis fibrosa may be regarded as evidence of increased parathormone secretion, the defect in the excretion of phosphorus seen in this patient indicates insensitivity of the renal tubules to the phosphaturic effect of parathormone; this defect, together with the typical facies suggest the diagnosis of pseudohypoparathyroidism. Hyperplasia of the parathyroids has been observed in this condition by Drake et al. (1939) and Bell et al. (1963). Tashjian, Frantz, and Lee (1966) have shown biologically and immunologically active parathormone in the parathyroid glands of two patients with pseudo-

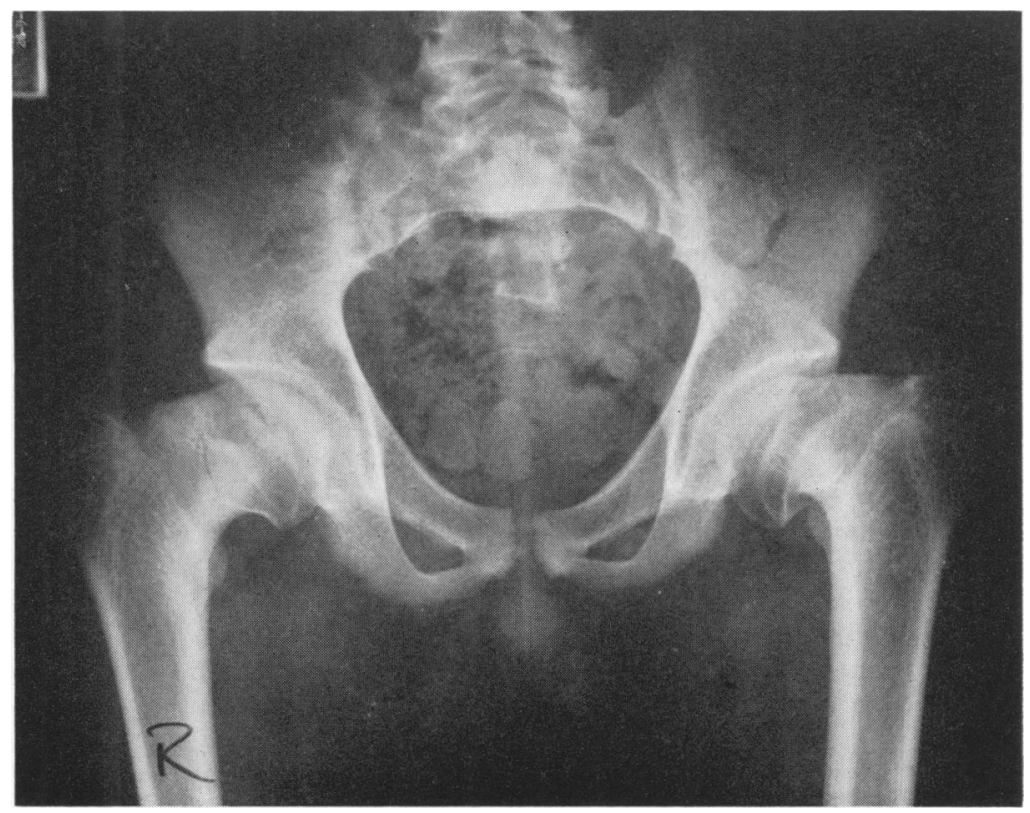

FIG. 5.-Pelvis, September 1967 (after 14 months' treatment). 
hypoparathyroidism, and that the thyroid vein blood of these patients contained much higher concentrations of parathormone than that of a control patient; however, the data were inadequate for the calculation of secretion rates. Nevertheless, it is probable that the osteitis fibrosa in the present case and in those described by Costello and Dent (1963), Kolb and Steinbach (1962), and Bell et al. (1963) is due to parathormone hypersecretion, secondary to either a tendency to low plasma calcium or to actual hypocalcaemia.

The plasma calcium level was at the lower limit of normal in our patient immediately before treatment; subnormal values were present in the similar patients referred to above. The reason for the hypocalcaemia in these cases is not clear, but it is postulated that it is due to the high level of plasma phosphorus resulting from tubular resistance to parathormone. Kolb and Steinbach (1962) showed that in their case reduction of plasma phosphorus by means of low phosphorus diet and probenecid was accompanied by a rise in plasma calcium. Infusion of phosphate lowers plasma calcium in acute experiments in both hypercalcaemic and normocalcaemic states (Dent, 1967; Goldsmith and Ingbar, 1966; Hebert et al., 1966). This lowering is due to the precipitation of calcium in some form in either bone or extra-osseous tissues. Hebert et al. suggested that precipitation was simply due to exceeding the $\left[\mathrm{Ca}^{+}+\right] \times\left[\mathrm{HPO}_{4}=\right]$ product in plasma, but this may well be an oversimplification. The alternative hypothesis, decrease in bone resorption on phosphate infusion, was shown not to apply in the studies of Pechet et al. (1967) in the rat.

In the present case the hyperphosphataemia was chronic rather than acute. Dent $(1962,1967)$ has shown that normocalcaemia may be maintained in primary hyperparathyroidism over many years by means of oral phosphate therapy. It is of interest to note that in idiopathic hypoparathyroidism chronic hyperphosphataemia and hypocalcaemia are sometimes associated with the development of increased bone density. This sort of osseous change does not develop in the type of patient described in this report presumably because the parathyroid glands are functioning and respond to the lowered plasma calcium by increased secretion, with ensuing osteitis fibrosa; in our patient it appears that increased parathyroid activity had, at the time of the initial study, succeeded in restoring the plasma calcium level to the lower limit of the normal range. Another possible factor in the tendency to hypocalcaemia in these cases is poor alimentary absorption of calcium, which was shown to be present in the patient of Bell et al. (1963).
Certain observations, however, do not support the suggestion that chronic hyperphosphataemia necessarily gives rise to hypocalcaemia. Wilber and Slatopolsky (1968) describe 2 teenage brothers with chronic hyperphosphataemia, 1 of whom had massive deposits of calcium around the large joints. Both patients had normal plasma calcium levels and at least one had a normal plasma alkaline phosphatase. Neither phalangeal subperiosteal erosions nor abnormal epiphyses were described in these patients, and plasma parathormone levels were not raised. Both patients had high tubular reabsorption of phosphate, diminishing on bovine parathormone infusion and on infusion with EDTA. It may be argued, therefore, that chronic hyperphosphataemia does not produce osteitis fibrosa, but as Wilber and Slatopolsky point out, it is possible that a higher proportion of the total plasma phosphate than normal may be in a bound, unionized, form. Alternatively, Wilber and Slatopolsky's patients may have an abnormality of bone accretion, the hyperphosphataemia succeeding in precipitating calcium only in extra-osseus sites and in amounts insufficient to cause hypocalcaemia. These arguments must at present remain speculative.

Pyrah, Hodgkinson, and Anderson (1966) suggested that thyrocalcitonin hypersecretion might be concerned in cases such as the one described in this paper. It has, indeed, recently been shown (Aliapoulios, Voelkel, and Munson, 1966) that the thyroid in pseudohypoparathyroidism contains a high concentration of thyrocalcitonin. Rather than this concentration indicating hypersecretion of the hormone, it is more probable that secretion is suppressed by hypocalcaemia, since Gittes, Munson, and Toverud (1966) and Gittes, Toverud, and Cooper (1968) have shown that the thyroid content of thyrocalcitonin rises during experimental hypocalcaemia resulting from parathyroidectomy. The effect of acute phosphate infusion on plasma calcium cannot be mediated via thyrocalcitonin because thyrocalcitonin inhibits bone resorption (Martin, Robinson, and MacIntyre, 1966), whereas, as mentioned previously, the hypocalcaemic effect of phosphate resorption is not mediated by such inhibition (Pechet et al., 1967). Finally, the high plasma phosphorus levels seen in this type of patient contrast with the hypophosphataemic effect of calcitonin.

Costello and Dent (1963) proposed an entirely different explanation for the metabolic abnormalities in their case. It has previously been suggested (Dent, 1962) on clinical grounds that the parathyroids secreted two hormones, one responsible for raising plasma calcium and lowering plasma 
phosphorus, and the other, in excess, causing osteitis fibrosa and raised plasma alkaline phosphatase. Costello and Dent postulated that in their case the first hormone was absent, but the second was being oversecreted. Consequently they introduced the term 'hypo-hyperparathyroidism'. A parathormone infusion test, which was not performed in their case, showed tubular unresponsiveness in the similar cases of Kolb and Steinbach (1962) and Bell et al. (1963). If two parathyroid hormones do exist (for which there is no direct evidence at the moment) then these cases show unresponsiveness to the tubular effects of the first hormone and not necessarily absence of it. For this reason we have preferred not to use the term 'hypo-hyperparathyroidism'. We did not think it justifiable to submit our patient to the risk of a protein reaction associated with a parathormone infusion test, since there was no doubt that the appropriate therapy was administration of vitamin $\mathrm{D}$.

An interesting feature of our patient is that he appears to be the only member of his family with evidence of this disorder. Bartter (1966) has pointed out the great variability of incidence of the physical and biochemical characteristics of pseudohypoparathyroidism within affected families. It is not clear whether the patient and his family represent an extreme example of this variability or whether he is a true sporadic case.

\section{Summary}

A case of pseudohypoparathyroidism is described which appears to show resistance to the action of parathyroid hormone on the kidney, but not to that on the bones. There was raised plasma phosphorus with renal phosphate retention, a low normal plasma calcium, and a raised alkaline phosphatase. Severe bone disease was present with radiological evidence of osteitis fibrosa.

There was healing of the bone lesions, a fall in alkaline phosphatase, and restoration of calcium and phosphorus levels towards normal on treatment with large oral doses of calciferol.

We are grateful to Dr. R. H. Balme for referring this patient, and to Professor C. E. Dent and Dr. Lyal Watson for pointing out the resemblance of this case to that of Costello and Dent and for stimulating discussion. We should also like to thank Dr. J. W. Landells for the bone biopsy report, and Mr. L. J. Butler for the dermatoglyphic studies.

\section{REFERENCES}

Aliapoulios, M. A., Voelkel, E. F, and Munson, P. L. (1966). Assay of human thyroid glands for thyrocalcitonin activity. f. clin. Endocr., 26, 897.

Albright, F., Burnett, C. H., Smith, P. H., and Parson, W. (1942). Pseudo-hypoparathyroidism: an example of the SeabrightBantam syndrome. Endocrinology, 30, 922.

Bartter, F. C. (1966). Pseudohypoparathyroidism and pseudopseudohypoparathyroidism. In The Metabolic Basis of Inherited Disease, 2nd ed., p. 1024. Ed. by J. B. Stanbury, J. B. Wyngaarden, and D. S. Fredrickson. McGraw-Hill, New York.

Bell, N. H., Gerard, E. S., and Bartter, F. C. (1963). Pseudohypoparathyroidism with osteitis fibrosa cystica and impaired absorption of calcium. f. clin. Endocr., 23, 759.

Costello, J. M., and Dent, C. E. (1963). Hypo-hyperparathyroidism. Arch. Dis. Childh., 38, 397.

Dent, C. E. (1962). Some problems of hyperparathyroidism. Brit. med. F., 2, 1495.

- (1967). Emergency treatment of hypercalcaemia. Lancet, 2 , 613.

Drake, T. G., Albright, F., Bauer, W., and Castleman, B. (1939). Chronic idiopathic hypoparathyroidism; report of six cases with autopsy findings in one. Ann. intern. Med., 12, 1751.

Elrick, H., Albright, F., Bartter, F. C., Forbes, A. P., and Reeves, J. D. (1950). Further studies in pseudo-hypoparathyroidism. Acta endocr. (Kbh.), 5, 199.

Forbes, A. P. (1964). Finger prints and palm prints (dermatoglyphics) and palmar-flexion creases in gonadal dysgenesis, pseudohypoparathyroidism and Klinefelter's syndrome. New Engl. F. Med., 270, 1268.

Garceau, G. J., and Miller, W. E. (1956). Osteochondrodystrophy as a result of, or in relation to pseudo-hypoparathyroidism. 7. Bone ft Surg., 38A, 131.

Gittes, R. F., Munson, P. L., and Toverud, S. U. (1966). Effect of plasma calcium on the thyrocalcitonin content of rat thyroid glands. Fed. Proc., 25, 496.

- Toverud, S. U., and Cooper, C. W. (1968). Effects of hypercalcemia and hypocalcemia on the thyrocalcitonin content of rat thyroid glands. Endocrinology, 82, 83.

Goldsmith, R. S., and Ingbar, S. H. (1966). Inorganic phosphate treatment of hypercalcemia of diverse etiologies. New Engl. $\mathcal{F}$. Med., 274, 1.

Hebert, L. A., Lemann, J., Jr., Petersen, J. R., and Lennon, E. J. (1966). Studies of the mechanism by which phosphate infusion lowers serum calcium concentration. F. clin. Invest., 45, 1886.

Kolb, F. O., and Steinbach, H. L. (1962). Pseudohypoparathyroidism with secondary hyperparathyroidism and osteitis fibrosa. f. clin. Endocr., 22, 59.

Martin, T. J., Robinson, C. J., and MacIntyre, I. (1966). The mode of action of thyrocalcitonin. Lancet, $1,900$.

Nordin, B. E. C., and Fraser, R. (1960). Assessment of urinary phosphate excretion. ibid., 1, 947.

Pechet, M. M., Bobadilla, E., Carroll, E. L., and Hesse, R. H. (1967). Regulation of bone resorption and formation. Amer. F. Med., 43, 696.

Pyrah, L. N., Hodgkinson, A., and Anderson, C. K. (1966). Primary hyperparathyroidism. (Critical review.) Brit. f. Surg., 53, 245.

Tashiian, A. H., Jr., Frantz, A. G., and Lee, J. B. (1966). Pseudohypoparathyroidism; assays of parathyroid hormone and thyrocalcitonin. Proc. nat. Acad. Sci. (Wash.), 56, 1138.

Wilber, J. F, and Slatopolsky, E. (1968). Hyperphosphatemia and tumoral calcinosis. Ann. intern. Med., 68, 1044. 